J. Lake Sci. (湖泊科学) , 2012, 24(5): 667-674

http: //www. jlakes. org. E-mail : jlakes@niglas.ac.cn

(C) 2012 by Journal of Lake Sciences

\title{
基于水平衡模型的呼伦湖湖泊水量变化
}

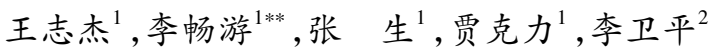 \\ ( 1 : 内蒙古农业大学水利与土木建筑工程学院, 呼和浩特 010018) \\ ( 2 : 内蒙古科技大学能源与环境学院,包头 014010)
}

\begin{abstract}
摘 要: 针对北方寒旱区呼伦湖水位下降、水面萎缩的现象, 根据气候特征, 利用月水量平衡模型探究湖泊水文过程并揭 示其变化规律. 在此基础上,利用不同气候条件下各水平衡项对于湖泊水位的影响程度确定水位升降的直接原因. 基于 1963-1980 年间水位的实测数据, 根据水量平衡原理及其他辅助计算判断出湖泊与周边区域存在着地下水的交换, 且具 有一定的规律性,即历年 11 月至次年 3 月期间的累积降雪融化渗人土壤中形成浅层径流补给湖泊, 而 $7 、 8$ 月份湖泊补给 周边草原. 基于以上规律, 根据周边坡面汇流、地下水与湖泊交换量的年内变化特征,利用水平衡方程式推算湖泊 $1981-$ 2008 年逐月水位变化,并与其他研究成果比较, 吻合度较高. 不同气候条件下, 径流量对于湖泊水位的影响程度最为突 出,是水位变化的主控因子.
\end{abstract}

关键词: 水量平衡模型;水位模拟; 呼伦湖

\section{Hydrological changes in Lake Hulun based on water balance model}

\author{
WANG Zhijie ${ }^{1}$, LI Changyou ${ }^{1}$, ZHANG Sheng ${ }^{1}$, JIA Keli ${ }^{1} \&$ LI Weiping ${ }^{2}$ \\ (1: Water Conservancy and Civil Engineering College, Inner Mongolia Agricultural University, Hohhot 010018, P. R. China) \\ (2: School of Environment and Energy Resources, Inner Mongolia University of Science and Technology, Baotou 014010, \\ P. R. China)
}

\begin{abstract}
In order to study the shrinkage of the Lake Hulun, monthly water balance model was used to analyze the characteristics and causes of water changes. Based on available continuous lake level monitoring data from 1963 to 1980 , there are exchange between groundwater of surrounding areas and lake water according to the principle of water balance and other auxiliary calculations. The exchange has a certain regularity, which is the accumulated snow of the period from November to March when snows begin to melt and then infiltrate the soil with the increase of temperature. This part of water recharges the lake in the form of subsurface flow in spring, which causes the lake water level increases slightly. The lake will recharge the surrounding prairie through strong evaporation after July. On the basis of above observations, the unknown items, i. e. the exchange and overland flow, were taken into balance equation as a constant to simulate water level. There is high goodness of fit between simulated values and related research results. Finally, the influence of precipitation, runoff and evaporation under different climate scenarios on lake water level were used to determine the cause of the drastic decrease of the lake level. The results show that decline of the lake water level after 2000 is mainly due to the sharp drop of river runoff.
\end{abstract}

Keywords: Water balance model; simulation of lake water level; Lake Hulun

近年来, 中国东北第一大湖一一呼伦湖及其周边流域在全球气候变化及人为非理性活动的双重影响下, 流域内生态水文过程紊乱.据监测,近 $5 \mathrm{a}$ 来,湖泊水位连续下降 $2.3 \mathrm{~m}^{[1-5]}$. 水量的不断减少造成水环境的逐步恶 化. 近 $10 \mathrm{a}$, 呼伦湖水质主要污染指标呈现出波动变化, 溶解氧有下降的趋势, 六价铬呈上升趋势, 硝酸盐基本持 平, 已呈中度富营养化水平 ${ }^{[6]}$. 湖周草原每年以 $5 \%$ 的速度退化, $1985-1997$ 年每年以 $10 \%$ 的面积加速退化 ${ }^{[7]}$.

* 国家自然科学基金项目 $(51069007,50969005,40901262)$ 、内蒙古自然科学基金项目 $(2010$ MS0713,2010MS0611)、 内蒙古自治区水利厅重点支持项目 (20080105) 和内蒙古教育厅科研项目 ( NJ09051) 联合资助. $2011-09-22$ 收 稿;2011-12-05 收修改稿. 王志杰,女,1983 年生, 博士研究生; E-mail : wangzhijie0807@ gmail. com.

** 通信作者;E-mail:nndlichangyou@ 163.com. 
秦伯强等 ${ }^{[8-9]}$ 和孙标 ${ }^{[10]}$ 先后计算了 $1959-1983$ 年、1963-2007 年年水量平衡项, 进一步用统计相关的 方法分析影响湖泊水位升降的主要因子, 均认为径流量丰枯直接影响湖泊水位的消长, 是湖泊变化的主控 因子, 而径流又由降雨来决定 ${ }^{[8-10]}$. 孙标认为呼伦湖除了大气降水与河川径流补给以外应存在地下水补 给 ${ }^{[10]}$. 李肿等 ${ }^{[11]}$ 采用彭曼公式估计了湖泊的水面蒸发,并建立了一个两月参数月水量平衡模型模拟湖周人 流, 地下水采用 1981 年的调查数据, 通过水量平衡计算, 模拟了湖泊月水量、水位变化, 重建了 $42 \mathrm{a}(1961-$ 2002 年) 的呼伦湖区水位序列.

关于呼伦湖的研究成果较少, 而且深度有限, 其原因一方面是人为因素的影响下, 流域内的水文过程比 较复杂; 另一方面是湖泊处于中国、蒙古、俄罗斯交界, 流域面积大, 相关资料系统性较差且难于收集. 虽然 问题被广泛关注,但研究深度和可信服的结论性认识有限.

本文在收集资料不断增加及数字化的基础上,利用水文研究最为基础的方法一一水量平衡原理, 重新 对呼伦湖流域逐月水量平衡进行分析计算, 并根据当地气候特征初步对地下水与湖水之间的交换进行量 化,同时归纳湖周坡面汇流、地下水与湖水交换量的年内变化特征,利用水量平衡方程模拟 1981-2008 年逐 月水位. 通过不同气候条件转化下, 各水平衡项对于水位变化的影响程度确定湖泊萎缩的主控因子.

\section{1 研究区域概况}

\section{1 地理位置与湖泊形态}

呼伦湖位于满洲里、新巴尔虎右旗、新巴尔虎左旗 (简称右旗、左旗) 之间,坐落于呼伦贝尔大草原中部. 湖面呈不规则长方形, 长轴为西南至东北方向, 湖长 $93 \mathrm{~km}$, 平均宽度 $25 \mathrm{~km}$, 周长 $447 \mathrm{~km}$, 当湖水位达到历史 较高水位 $545.33 \mathrm{~m}$ 时, 蓄水量为 $138 \times 10^{8} \mathrm{~m}^{3}$, 湖水面积 $2339 \mathrm{~km}^{2}$, 平均水深 $5 \sim 6 \mathrm{~m}^{[12]}$. 湖盆西北部为一条 东北向西南的低山丘陵带, 北端、南端和东面环湖一带为较广阔的湖滨平原(图 1 ).

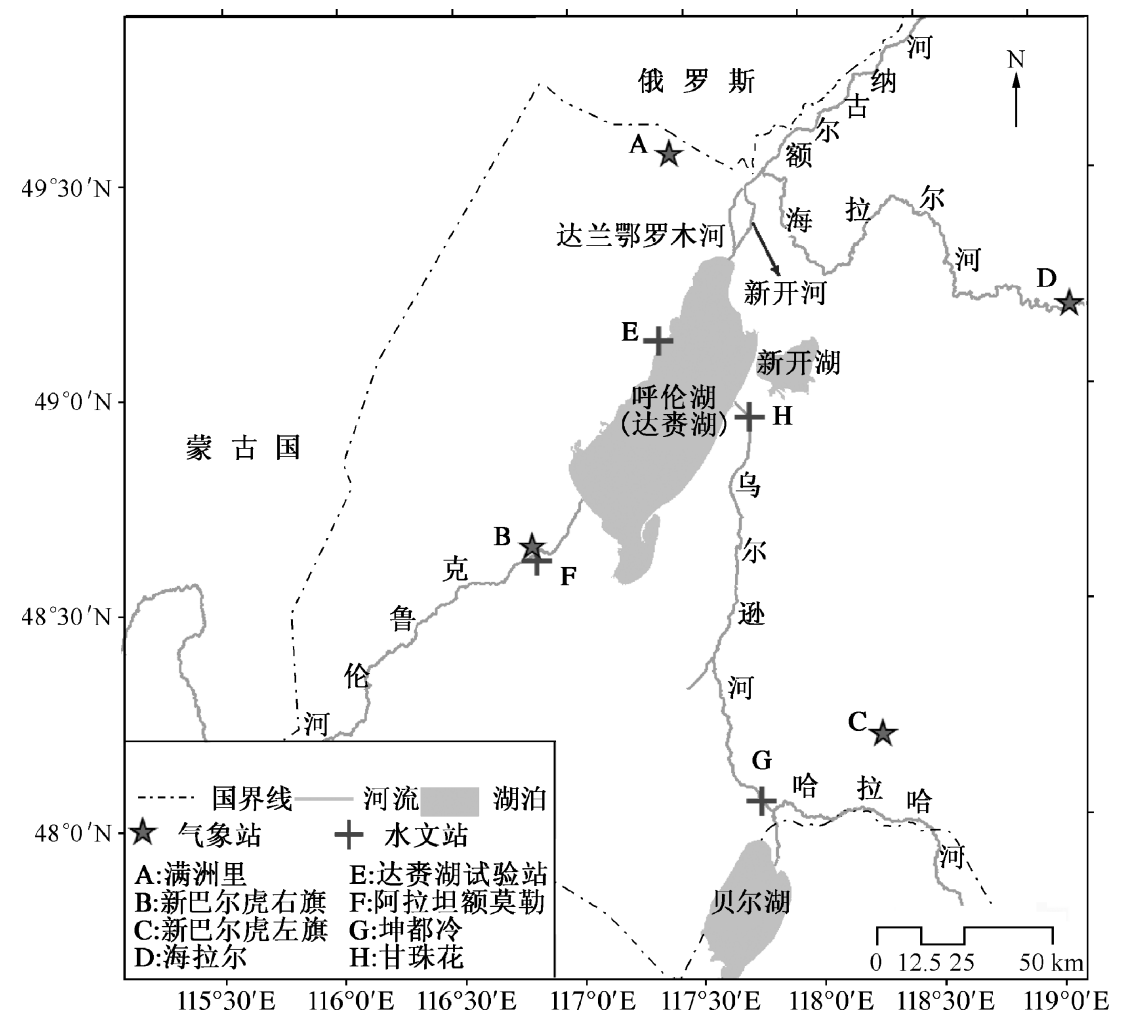

图 1 呼伦湖地理位置及水文、气象站点分布

Fig. 1 Location of Lake Hulun and hydrologic, meteorological stations 


\section{2 流域水系}

呼伦湖水系是额尔古纳水系的组成部分, 主要包括哈拉哈河、贝尔湖、乌尔逊河、克鲁伦河、达兰鄂罗木 河、新开河等主要支流. 哈拉哈河发源于大兴安岭西麓, 河道分为两支,一支向西北流人乌尔逊河, 另一支向 南流人贝尔湖. 贝尔湖是中蒙两国共有的湖泊, 大部分在蒙古境内, 仅西北部的 $40.26 \mathrm{~km}^{2[10]}$ 为我国所有. 乌 尔逊河是连接贝尔湖和呼伦湖的通道, 全长 $223 \mathrm{~km}$. 克鲁伦河发源于蒙古国肯特山南麓, 河长 $1264 \mathrm{~km}$. 达兰 鄂罗木河是连接呼伦湖与额尔古纳河的吞吐性河流,全长 $25 \mathrm{~km} .1958$ 年前, 海拉尔河的部分水量通过达兰 鄂罗木河流人达秉湖. 由于湖泊水位猛烈上涨, 影响了附近扎秉诺尔煤矿的正常开采, 于 1958 年 7 月 15 日 开始堵河, 从此截断了呼伦湖与额尔古纳河、海拉尔河地表径流之间的联系. 堵河后, 湖水位更加猛烈地上 涨, 为了缓解湖水涨势, 于 1965 年 6 月开始修建 “达麥湖泄水工程”, 即新开河,于 1971 年 9 月全部建成并投 人使用 ${ }^{[12]}$.

\section{3 气候}

呼伦湖区属于中温带大陆性季风气候, 年平均气温为 $-5 \sim 3^{\circ} \mathrm{C}$, 降水量为 $247 \sim 319 \mathrm{~mm}$, 集中在 $6-9$ 月, 占全年总量的 $80 \% \sim 86 \%$, 最大湿度可达 $80 \%$, 最大风速为 $5.35 \mathrm{~m} / \mathrm{s}$, 平均蒸发量为 $1500 \mathrm{~mm}(1960-$ 2009 年统计).

\section{2 数据}

\section{1 水文、气象}

1950s 末呼伦湖周边设立四个水文站,分别为阿拉坦额莫勒、坤都冷、甘珠花和达麥湖实验站,其中甘珠 花站,达妻湖实验站分别于 1971、1980 年撤销, 其他两个仍在使用中. 气象站位于湖周临近旗县境内 (图 1 ).

\section{2 水位一面积一库容关系}

孙标选择呼伦湖 1986-2007 年共 $24 \mathrm{a}$ 的 Landsat 影像资料,应用秋季湖水的热对流原理, 以太阳辐射 波段和与湖水热红外辐射波段进行多波段组合建立水深反演模型, 获得湖底高程数据. 同时, 采用最大似然 法提取水面面积 ${ }^{[10]}$. 基于此数据, 绘制水位一水面面积一库容关系曲线 (图 2 ) 及多年水陆界面叠加图 (图 $3)$. 呼伦湖水面大小随着水位的变化而变化,并不存在水生植物沉积、沼泽化进程等现象, 湖泊水面萎缩主 要体现在坡度小水深浅的左下角湖湾和东岸的湖滩 ${ }^{[10]}$.

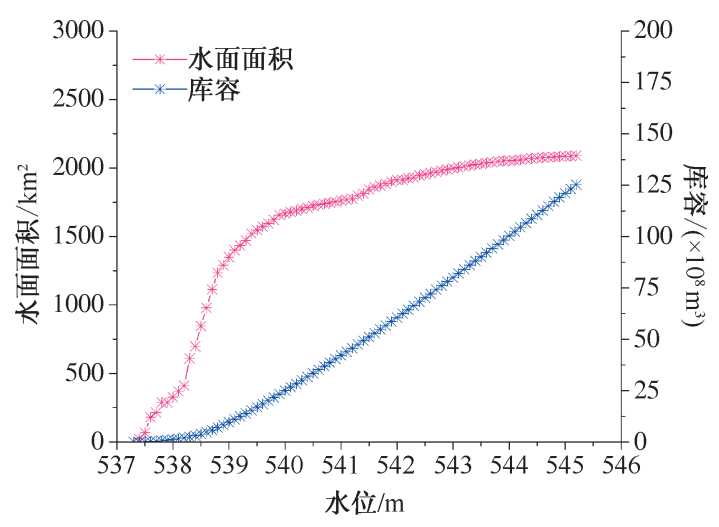

图 2 水位一面积一库容关系曲线

Fig. 2 Relationships between lake water level, area and volume

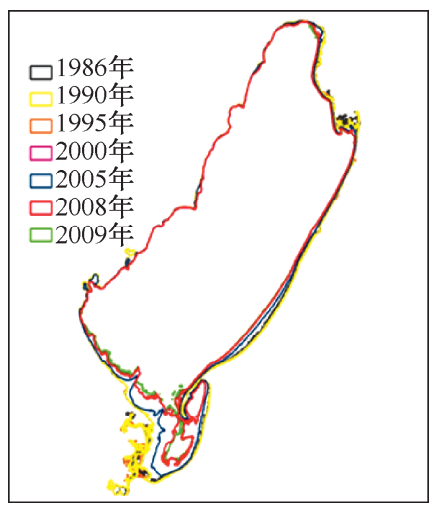

图 3 湖泊水面轮廓变化

Fig. 3 Water area of Lake Hulun

\section{3 水量平衡模型}

湖泊水量平衡方程 ${ }^{[13]}$ 为:

$$
\frac{\Delta V}{\Delta t}=A(h)(P-E)+Q_{\text {in }}+Q_{\text {out }}
$$


式中, $\Delta t$ 为时间步长 (天、月、年); $\Delta V=V_{t+1}-V_{t}$, 为湖泊库容变化量 $\left(\mathrm{m}^{3}\right) ; A$ 为湖泊水面面积 $\left(\mathrm{m}^{2}\right)$, 是水位 $h(\mathrm{~m})$ 的函数; $P$ 为湖面降雨量 $(\mathrm{mm}) ; E$ 为湖面蒸发量 $(\mathrm{mm}) ; Q_{\text {in }}$ 为人湖水量 $\left(\mathrm{m}^{3}\right) ; Q_{\text {out }}$ 为出湖水量 $\left(\mathrm{m}^{3}\right)$.

呼伦湖处于国家自然保护区内, 工矿企业较少, 人口稀疏,所以工农业用水忽略不计,水量平衡方程表 示为:

$$
\frac{\Delta V}{\Delta t}=A(h)(P-E)+Q_{\text {rin }}+Q_{\text {overland }}+Q_{\text {gin }}-Q_{\text {rout }}-Q_{\text {gout }}=A(h)(P-E)+Q_{\text {rin }}-Q_{\text {rout }}+\beta
$$

式中, $Q_{\text {rin }} 、 Q_{\text {rout }}$ 为河流人湖、出湖水量; $Q_{\text {gin }} 、 Q_{\text {gout }}$ 为地下水人、出湖水量, $Q_{\text {overland }}$ 为湖周坡面汇流. 其中坡面汇 流及湖泊与地下水的交换量为未知项,这里归为一项 ${ }^{[14-15]}$, 用模型余项 ${ }^{[10]} \beta$ 表示 :

$$
\beta=Q_{\text {overland }}+Q_{\text {gin }}-Q_{\text {gout }}=\frac{\Delta V}{\Delta t}-A(h)(P-E)-Q_{\text {rin }}+Q_{\text {rout }}
$$

\section{4 水平衡项}

\section{1 蒸发}

蒸发是水平衡的重要组分, 其计算的精度决定着水平衡结果的可靠性. Penman 公式是目前世界上使用 最为广泛的公式之一, 并被 FAO (Food and Agricultural Organization of United Nations) 推荐使用,其表达 式 ${ }^{[16]}$ 为:

$$
E_{\mathrm{PEN}}=\frac{\Delta}{\Delta+\gamma} \cdot \frac{R_{n}}{\lambda}+\frac{\gamma}{\Delta+\gamma} \cdot \frac{6.43\left(f_{u}\right) D}{\lambda}
$$

式中, $E_{\mathrm{PEN}}$ 为水面蒸发量 $(\mathrm{mm}) ; R_{n}$ 为净辐射 $\left(\mathrm{MJ} /\left(\mathrm{m}^{2} \cdot \mathrm{d}\right)\right) ; \Delta$ 为饱和水汽压梯度 $\left(\mathrm{kPa} /{ }^{\circ} \mathrm{C}\right) ; \gamma$ 为湿度常数 $\left(\mathrm{kPa} /{ }^{\circ} \mathrm{C}\right) ; \lambda$ 为蒸发潜热; $f_{u}=a_{u}+b_{u} u$, 为风速函数; $a_{u} 、 b_{u}$ 为风速函数系数; $u$ 为 $2 \mathrm{~m}$ 处风速 $(\mathrm{m} / \mathrm{s}) ; D=e_{\mathrm{s}}-$ $e_{\mathrm{a}}$, 为水汽压饱和差; $e_{\mathrm{s}}$ 为饱和水汽压; $e_{\mathrm{a}}$ 为实际水汽压. 计算过程所使用的经验参数取自我国学者对于 Pen$\operatorname{man}$ 公式的修订结果以及国外的相关研究成果 ${ }^{[17-18]}$.

计算四个气象站 1960-2008 年逐日水面蒸发,将其结果与达责湖实验站观测值做相关性分析, 结果显 示相关性均较好,右旗、左旗、满洲里的折算系数为 0.61 左右,与已有研究结果 ${ }^{[11,19-21]}$ 接近,而海拉尔仅为 0.4251 , 说明该区蒸发明显小于湖面. 所以,本文选择满洲里、右旗、左旗的均值作为湖面蒸发量,计算值与 实测值相关性达到了 0.93 .

\section{2 降雨}

对达妻湖实验站与气象站同期降雨进行相关性分析,其中满洲里、右旗与实验站年、季、月降雨相关性 最好, 相关系数分别达到 0.71 和 0.73 , 且两者分别位于湖泊的北、南方向, 距离湖面较近, 所以将两者均值 作为湖面降雨.

\section{3 径流}

克鲁伦河、乌尔逊河上水文站观测逐日流量累加得到月、年径流量. 新开河流量没有实测数据, 目前有 两种关于流量的记载,第一种, 当水位超过 $544.8 \mathrm{~m}$ 时, 按照闸门设计流量泄流, 即 $40.7 \mathrm{~m}^{3} / \mathrm{s}^{[11]}$; 第二种, 自 1971 年 9 月至 1979 年 9 月通过新开河泄水, 1980 年 5 月至 1984 年通过新开河补水.

\section{5 水量计算}

由于缺少新开河流量、地下水及坡面汇流的观测数据, 水平衡式 (2) 中的余项 $\beta$ 以及河流出人量中的新 开河部分为未知项. 忽略所有未知项, 水平衡式表示为:

$$
V_{i+1}=V_{i}\left(h_{i}\right)+A_{i}\left(h_{i}\right)\left(P_{i}-E_{i}\right)+Q_{\text {rini }}-Q_{\text {routi }}
$$

式中, 以月 $(i)$ 为单位, 初始水位为 1962 年 12 月观测水位, 推算 1963-1980 年逐月水位,将其与达责湖实验 站观测值比较 (图 4), 发现两者的变化趋势基本一致,但是在 1971-1979 年间,推算值高于实测值,而 1980 年 4 月后恰恰相反. 这与新开河 1971-1979 年间泄水, 1980-1984 年间补水的记载相一致,所以,两者之 
间的差距可能是新开河的流量造成的. 1963-1970 年 间, 4-7 月推算水位低于实测值, 而其他时间则高于实 测值. 此段时间内, 仅有余项为未知项, 则根据实测水 位利用式 (3) 计算余项. 余项在 7 月前呈正值, 5 月份 达到最大, 8 月份达到负值最大, 11 月到次年 2 月均呈 较小负值 (图 5), 并且与其他水平衡项没有直接的 关系.

由于湖泊周边流域全部为草原, 与参照作物蒸发率 的定义相近, 利用 Penman 公式 ${ }^{[16,22]}$ 分别计算 $1960-$ 2008 年湖周四个气象站所在草原的逐日蒸散发量, 取其平均值与逐日降雨量比较. 根据季节性气候特征 可知, 11 月至次年 5 月, 余项仅为地下水与湖泊水的 交换量, 6-9 月还包括了坡面汇流. 1963-1970 年 间各水平衡项的逐月平均值变化特征表明, 自 11 月 至次年 3 月, 历时 5 个月的累积降雪随着温度的回 升, 逐渐开始融化并渗人土壤, 形成了地下浅层径流 汇人湖泊, 而在 $7 、 8$ 月份, 湖泊在强烈蒸发的作用下 补给周边草原 ${ }^{[23]}$.

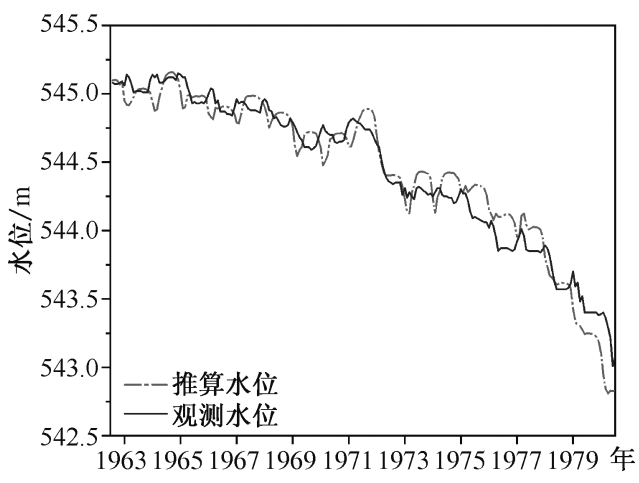

图 4 1963-1980 年水平衡推算水位 (忽略湖周 坡面汇流、地下水与湖水交换、新开河流量） 与实测水位对比

Fig. 4 Observed and simulated lake levels of Lake Hulun during 1963 - 1980( The simulated level obtained by neglecting the residue item, including overland flow, exchange between groundwater and lake and runoff of Xinkai River)
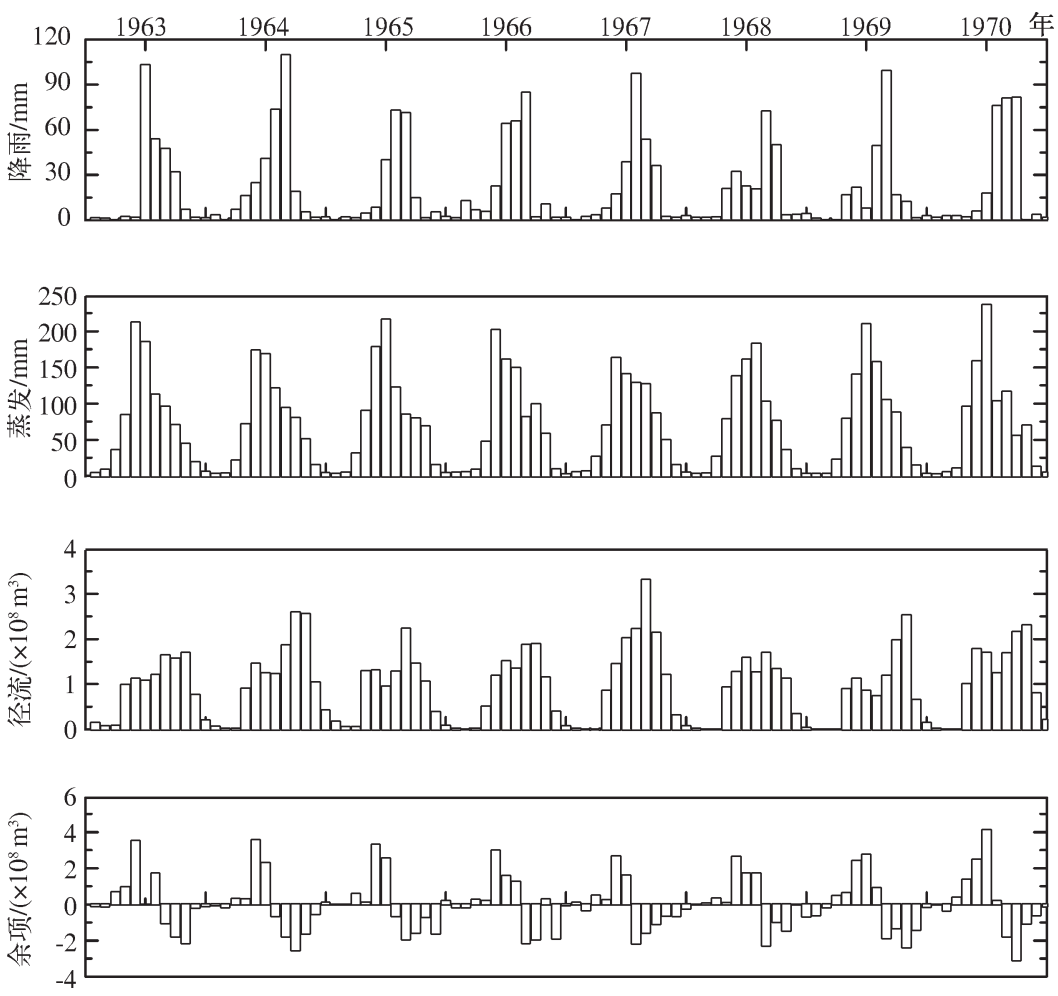

图 5 1963-1970 年逐月水平衡项

Fig. 5 The water balance components during 1963-1970 


\section{6 水位推算}

\section{$6.11981-2008$ 年水位模拟}

余项的变化具有一定的周期性, 将其各月的多年平均值作为常数代人水量平衡式 (2), 以 1980 年 12 月为 计算起点,推算 1981-2008 年间逐月水位, 将计算结果与已有研究做对比 (图 6), 各月余项 $\beta$ 的取值见表 2 .

表 2 逐月余项平均值

Tab. 2 Mean monthly model residue

\begin{tabular}{|c|c|c|c|c|c|c|c|c|c|c|c|c|}
\hline & 1 月 & 2 月 & 3 月 & 4 月 & 5 月 & 6 月 & 7 月 & 8 月 & 9 月 & 10 月 & 11 月 & 12 月 \\
\hline 余项 $/\left(\times 10^{8} \mathrm{~m}^{3}\right)$ & -0.18 & -0.06 & 0.38 & 1.54 & 2.34 & 1.74 & -0.19 & -1.94 & -1.37 & -1.24 & -0.39 & -0.06 \\
\hline 标准差 & 0.11 & 0.11 & 0.30 & 0.46 & 0.51 & 0.33 & 0.46 & 0.53 & 0.60 & 0.47 & 0.44 & 0.21 \\
\hline
\end{tabular}
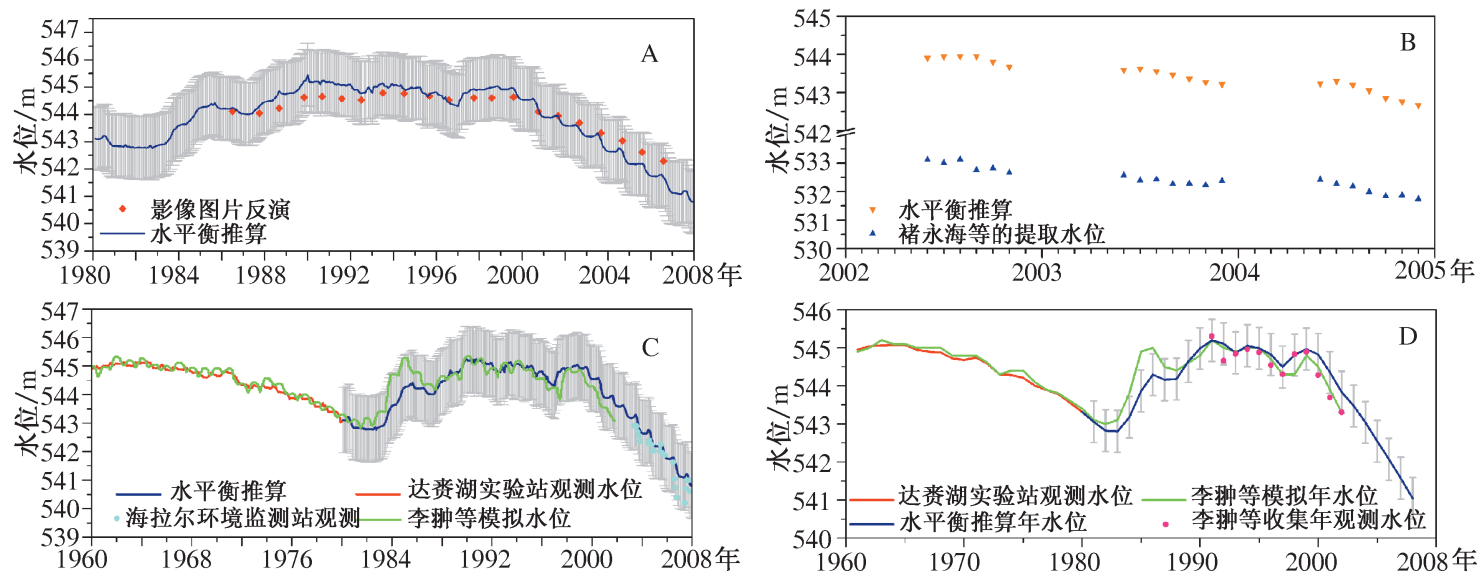

图 6 水平衡推算水位与已有研究结果的对比

Fig. 6 Comparison of simulated water levels and those of other studies

呼伦湖水位 1981-1990 年期间呈缓慢上升趋势, 水位从 $543 \mathrm{~m}$ 升至 $545 \mathrm{~m}$,之后则保持平稳变化状态, 而自 1999 年开始急剧下降,到 2008 年已降至 $540.85 \mathrm{~m}$ (图 6A), 标准差为 $1.14 \mathrm{~m}$. 水平衡推算水位与文献 [10] 中利用影像图片解译水面面积 ${ }^{[10]}$ 及水位一面积一库容关系得出的水位变化趋势一致,但也存在一定差 距, 最大为 $0.65 \mathrm{~m}$, 其原因是影像获取当天水位与月平均水位存在差距. 另外,水位一面积一库容关系的精确 程度也直接关系着拟合结果的好坏.

褚永海等 ${ }^{[24]}$ 利用 $3 \mathrm{a}(2002-2004$ 年) Jason-1 测高数据, 根据简单的数据编辑准则, 提取呼伦湖水域 511 月平均水位信息 (图 6B), 与本文推算的水位变化趋势较为接近,但是数值差距较大,最大可达 $11.54 \mathrm{~m}$, 这与计算模型、各种参数及参照基准面的选择有着直接的关系.

文献 $[11,25]$ 同样对呼伦湖的水量平衡进行了计算,但是所用的方法与数据与本文存在着差异性及相似 性,主要体现在以下几点;第一,湖面蒸发的计算: 李朋等根据满洲里气象站数据利用彭曼公式计算 $1960-$ 1998 年的蒸发量,并将其作为湖面蒸发,1998 年后用阿拉坦额莫勒水文站观测值折算获得; 第二,湖面降雨 量的计算: 李㹨等 ${ }^{[23]}$ 采用泰森多边形法, 以满洲里、坤都冷站、阿拉坦额莫勒站和碰岗站为中心划分为四大 区域,湖面降雨按对应站的降雨计算;第三,与本文相似的做法是将湖周地表径流和地下径流合并为一项, 分别表示为湖周径流和余项,但不同的是李䛆等的地表径流采用双参数月水量平衡计算,地下径流采用 1981 年丰水年的调查数据代替 ${ }^{[11,25]}$. 水位的主要变化趋势是一致的,但是也存在着较大的差距,最大可达 $1 \mathrm{~m}$, 主要位于水位发生急剧变化的情况下 (图 6C、D). 这可能与余项代表性强弱存在关系. 余项是在 1963-1980年间水文过程下计算的平均值,期间没有发生极端天气, 水文过程也没有剧烈的变动, 所以当气 
候、水文系统发生较大的变化时,余项的代表性会降低,进而导致水位的巨大差距. 2003-2006 年,本文推算 水位与海拉尔环境监测站的观测水位吻合较好,之后的差距较大,这与水位的测量位置不固定有关.

\subsection{9 年后水位降低原因探讨}

1960-2009 年内,水位、径流、降雨三者的变化趋势存在着一致性(图 7), 可分三个阶段:1) 1960-1980 年:水位从 $545.2 \mathrm{~m}$ 缓慢下降到 $544.8 \mathrm{~m}$,降雨和径流分别在 $263.02 \mathrm{~mm} 、 10.267 \times 10^{8} \mathrm{~m}^{3}$ 上下波动,但幅度不大;2 ) 1981-2000 年: 水位保持在 $544.4 \mathrm{~m}$, 降雨、径流波动幅度较大, 平均值分别为 $263.59 \mathrm{~mm} 、 13.94 \times 10^{8} \mathrm{~m}^{3} ; 3$ ) 2001-2009 年:均呈急剧下降趋势,水位降至 $542.2 \mathrm{~m}$,降雨径流减小到 $199.16 \mathrm{~mm} 、 3.32 \times 10^{8} \mathrm{~m}^{3}$.

根据以上降雨、径流的变化情况, 提取出平均、极湿、极干气候特征,代表时段为 1963-1970 年、19881990 年、2000-2005 年, 计算各代表时段内降雨、蒸发、径流的多年逐月平均值构建全年水平衡系列.

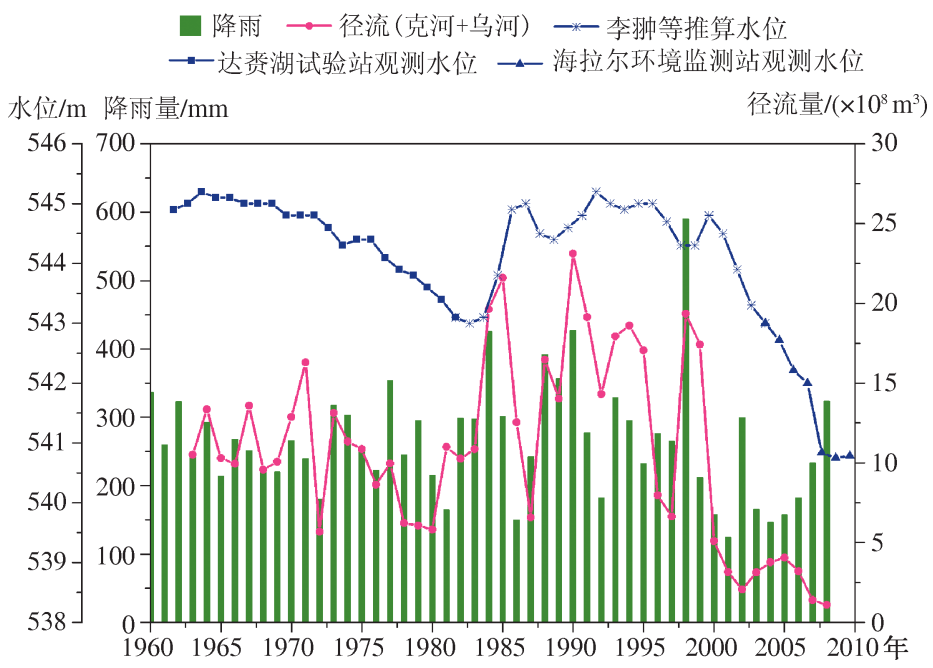

图 7 1960-2008 年湖泊水位、湖面降雨、河流径流量变化

Fig. 7 Annual precipitation, water level and runoff of river during 1960-2008

为了确定 1999 年后水位突然急剧降低的原 因,分析 2000-2005 年间气候条件下降雨、径流、 蒸发对水位的影响程度 (图 8 ), 结果显示, 极干 气候下的降雨或蒸发的变化不足以引起水位的 剧烈变化. 然而, 径流导致水位降低的幅度占整 个极干气候下水位变化的 $90 \%$. 因此,可以断 定,1999 年后水位急剧降低的主要原因为河流 (克鲁伦河、乌尔逊河) 径流量的锐减, 这与孙 标 ${ }^{[10]}$ 利用库容差与其他水平衡项的相关性分析 的结果相符.

\section{7 结论}

水平衡计算过程中,地表坡面汇流及地下水是 最为难于确定的水平衡项, 将其合并为一项进行整 体计算, 减少了变量个数, 方便了计算. 本研究区属 于寒早区,季节性气候明显, 在其他水平衡项确定

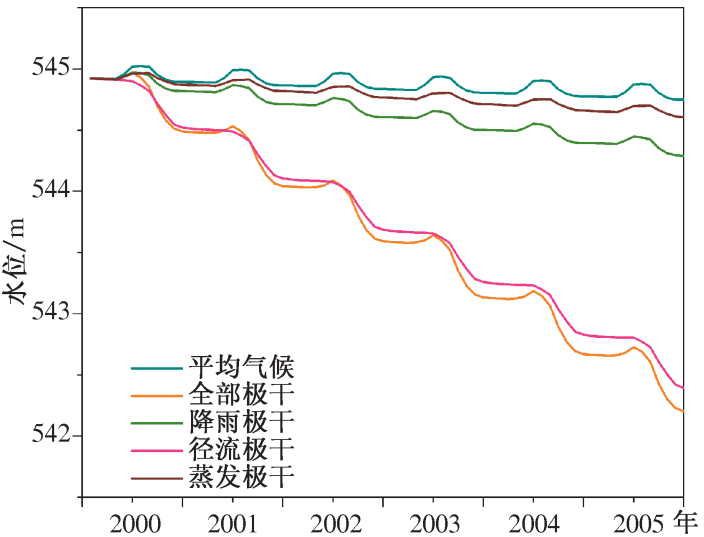

图 8 气候特征之间转变对水位的影响

Fig. 8 The influence of transition between different climate scenarios on water level 的基础上,根据不同季节降雨、蒸发的变化及对比关系,划分坡面汇流及地下水与湖水的交换量.

每年的 4-7 月,湖水位稍有增加, 参考辅助计算结果可知, 相比较降雨、径流、蒸发, 地下水对湖水的补 
给发挥了更为重要的作用,其来源于 11 月至次年 3 月,历时 5 个月的累积降雪随着温度的回升, 逐渐开始融 化并渗人土壤, 形成了地下浅层径流汇人湖泊. $7 、 8$ 月份, 降雨、径流达到峰值的情况下, 湖泊库容却有所减 少, 这是由于湖周大面积草原在强烈蒸发的作用,地下水位降低, 湖泊开始补给周边草原.

将无数据的水平衡项合并为一项,带人水量平衡方程中推算水位, 虽然包含了年内变化特征, 但是其变 化气候条件下的代表性有限, 直接影响了模拟结果的精度.

平均、极湿、极干不同气候条件下,各水平衡项对湖泊水位的影响程度表明,2000 年后湖泊极速萎缩的 主要原因是河流径流的锐减,与降雨一致、蒸发相反,是气候变化的直接后果.

综合以上,水量平衡模型作为一种最基础的方法用于水文系统内水量分布,湖泊水位变化原因、影响因 素以及水位模拟方面的研究具有独特的效果,特别是对于资料缺乏的流域.

\section{8 参考文献}

[1] 高 平. 北方第一大淡水湖呼伦湖今年水位上涨喜人. 光明日报, $2008-8-3(5)$.

[ 2 ] 高立洪. 拯救呼伦湖. 中国水利报, 2004-9-11.

[ 3 ] 丁 铭. 中国东北部第一大湖水环境恶化. 人民日报海外版, 2003-12-30.

[4] 丁 铭. 呼伦湖 20 年内将变成盐碱湖. 新华每日电讯, 2003-12-21(8).

[5] 马瑞芳. 气象监测发现呼伦湖水域萎缩. 中国气象报, 2007-3-1(1).

[6] 韩向红, 杨 持. 呼伦湖自净功能及其在区域环境保护中的作用分析. 自然资源学报, 2002,(6)：684-690.

[ 7 ] 颜文博, 张洪海,张承德. 达责湖自然保护区湿地生物生境保护. 国土与自然资源研究, 2006, (2) : 47-48.

［8］秦伯强,王苏民. 呼伦湖的近期演变及其与气候的关系. 干旱区资源与环境, 1993, 7(2):1-9.

[ 9 ] 秦伯强,王苏民. 呼伦湖的近期扩张及其与全球气候变化的关系. 海洋与湖沼, 1994, 25 (3) :280-287.

[10］孙 标. 基于空间信息技术的呼伦湖水量动态演化研究 [学位论文]. 呼和浩特: 内蒙古农业大学, 2010.

[11］李 棚, 马 巍, 叶柏生等. 呼伦湖水面蒸发及水量平衡估计. 水文, 2006, (5) : 41-44.

[12］徐占江, 姜风元, 赵好文等. 呼伦湖志. 长春: 吉林文史出版社, 1989: 660-665.

[13 ] Troin M, Vallet-Coulomb C, Sylvestre F et al. Hydrological modelling of a closed lake(Laguna Mar Chiquita, Argentina) in the context of 20th century climatic changes. Journal of Hydrology, 2010, 393(3/4) : 233-244.

[14] Kumambala PG, Ervine A. Water balance model of Lake Malawi and its sensitivity to climate change. The Open Hydrology Journal, 2010, 4 : 152-162.

[15] Kebede S, Travi Y, Alemayehu T et al. Water balance of Lake Tana and its sensitivity to fluctuations in rainfall, Blue Nile basin, Ethiopia. Journal of Hydrology, 2006, 316(1/2/3/4) : 233-247.

[16] Shuttleworth WJ. In :Maidment DR ed. Evaporation. New York: McGraw-Hill, 1993: 4.1-4. 53(Chapter4).

[17] 童宏良. 我国蒸发力计算的气候学方法. 南京气象学院学报, 1989, (1): 19-33.

[18 ] Valiantzas JD. Simplified versions for the Penman evaporation equation using routine weather data. Journal of Hydrology, $2006,331(3 / 4): 690-702$.

[19］施成熙, 牛克源. 水面蒸发折算系数研究. 地理科学, 1986, 6(4) : 305-313.

[20］盛 琼, 申双和, 顾 泽. 小型蒸发器的水面蒸发量折算系数. 南京气象学院学报, 2007, 30(4): 561-565.

[21] 张武忠, 张少波,王诗俊. 呼伦贝尔市水面蒸发量折算系数分析. 东北水利水电, 2006, (4) : 26-27.

[22] Calanca P, Smith P, Holzkamper A et al. Reference evaporation and its application in agrometeorology. Agrarforschung Schweiz, 2011, 2(4) : 176-183.

[23] 王志杰, 李畅游, 李卫平等. 内蒙古呼伦湖水量平衡计算与分析. 湖泊科学, 2012, 24(2) : 273-281.

[24] 褚永海, 李建成, 姜卫平等. 利用 Jason-1 数据监测呼伦湖水位变化. 大地测量与地球动力学, 2005, (4) : 11-16.

[25] 李 翀, 马 巍, 史晓新等. 呼伦湖水位、盐度变化(1961-2002 年). 湖泊科学, 2006, (1) : 13-20. 